\title{
ANALISIS PERMASALAHAN MAHASISWA PROGRAM STUDI PPKN DALAM MENGIKUTI PRAKTIK PEMAHAMAN HUKUM
}

\author{
${ }^{1}$ Neneng Rika Jazilatul Kholidah ${ }^{2}$ Sarjono \\ 1neneng_rika@ikippgribojonegoro.ac.id \\ 1jazilarika@yahoo.co.id \\ 22sarjono-1956@yahoo.com \\ ${ }^{12}$ IKIP PGRI Bojonegoro Jl. Panglima Polim No.46 Bojonegoro
}

\begin{abstract}
Education is one of very important parts of human life in general. Education is able to eradicate ignorance and it's also able to uphold human dignity as a creature that is endowed with a healthy mind and perfect physical. The purpose of this research is to find out the problems faced by civic study program students in following the practice of lawunderstanding in the Bojonegoro District Court. This type of research uses descriptive qualitative approach. The research subjects were students of the fifth semester of civicstudy program. Data collection techniques through interviews, observation and documentation. Data analysis techniques using an interactive model. Based on the results of research on the problemsanalysis of civic study program students in following the practice of lawunderstanding in the Bojonegorodistrict court is incomplete debriefing, unclear information related to the time of implementation,proposal preparation for law understanding practices, remained active although in the middle of covid-19pandemics, less role of the supervisor, long distance traveled, compilation of law understanding practice reports.
\end{abstract}

Keywords: students, practice, law

\begin{abstract}
Abstrak
Pendidikan merupakan salah satu bagian yang sangat penting bagi kehidupan manusia pada umumnya. Pendidikan mampu memberantas suatu kebodohan dan juga mampu menjunjung martabat manusia sebagi makhluk yang dianugerahi sebuah akal yang sehat serta fisik yang sempurna. Tujuan dari penelitian ini adalah untuk mengetahuai permasalahan yang dihadapi oleh mahasiswa program studi PPKN dalam mengikuti praktik pemahaman hukum di Pengadilan Negeri Bojonegoro. Jenis penelitian menggunakan deskriptif dengan pendekatan kualitatif.Subjek penelitian yaitu mahasiswa program studi P PPKN semester lima.Teknik pengumpulan data melalui wawancara, observasi dan dokumentasi. Teknik analisis data menggunakan model interaktif. Berdasarkan hasil penelitian tentang analisis permasalahan mahasiswa program studi PPKN dalam mengikuti praktik pemahaman hukum di pengadilan negeri Bojonegoroadalah kurang lengkapnya pembekalan, informasi yang kurang jelas terkait waktu pelaksanaan, Penyusunan proposal praktik pemahaman hukum,tetap aktif meski ditengah pandemi covid-19, peran dosen pembimbing yang kurang maksimal, jarak tempuh yang jauh, penyusunan laporan praktik pemahaman hukum.
\end{abstract}

Kata kunci : mahasiswa,praktik, hukum 


\section{PENDAHULUAN}

Pendidikan merupakan salah satu bagian yang sangat penting bagi kehidupan manusia pada umumnya. Pendidikan mampu memberantas suatu kebodohan dan juga mampu menjunjung martabat manusia sebagi makhluk yang dianugerahi sebuah akal yang sehat serta fisik yang sempurna. Tanpa pendidikan manusia akan tertinggal oleh perkembangan jaman yang saat ini semakin bertambah maju dalam bidang teknologinya. Pendidikan sangatlah berpengaruh baik terhadap diri sendiri maupun sekitar. Pendidikan diartikan sebagai proses sosialisasi yaitu sebagai sarana untuk melanjutkan sebuah eksistensi sebagai seorang manusia. Pendidikan bukan tentang sebuah gengsi tapi tentang nasib diri sendiri. Melalui sebuah pendidikan seseorang akan mampu mengerti, memahami, dan memiliki sikap sopan dan santun jika dalam bahasa jawa berarti unggah-ungguh. Pendidikan mampu mentransformasikan seseorang menjadi manusia yang mampu berinterksi dengan masyarakat sekitar maupun dengan masyarakat yang ada diluar. Bahwasannya generasi muda memiliki peranan penting dalam hal menentukan baik buruknya pada kehidupuan yang akan datang. Jika dirasa tingkat pendidikan yang dimiliki para generasi muda saat ini baik maka perlu adanya sebuah cara yang tepat agar bertahan dan semakin meningkat. Namun jika generasi muda saat ini tidak peduli dengan pendidikan maka tugas kita adalah bagaimana membawa mereka untuk mengenalkan peradaban yang baik, dan semua itu bisa didapatkan dengan cara memiliki pendidikan yang mumpuni.

Perkembangan dunia pendidikan terutama pendidikan tinggi di Indonesia yang meningkat pesat,menyebabkan semakin banyak pula jumah siswa yang melanjutkan pendidikannya di pendidikan tinggi (Effrisanti, 2015). Hal ini membuktikan bahwa pengalaman pendidikan sangatlah perlu terutama di jenjang perguruan tinggi. UndangUndang Dasar Republik Indonesia (UUD 45) telah mengamanatkan bahwa penyelenggaraan pendidikan nasional harus dapat mencerdaskan kehidupan bangsa. Esensi amanat UUD 45 ini kemudian dituahkan dalam pasal 1 Undang-Undang No.12 Tahun 2012 tentang pendidikan tinggi, dimana pendidikan tinggi harus dapat menciptakan suasana yang memungkinkan mahasiswa mengembangkan potensi diri dalam memperkuat pengetahuan dan keterampilan yang diperlukan dirinya, masyarakat, bangsa dan negara. Pendidikan merupakan sebuah proses dari suatu pengembangan akan kemampuan diri seseorang serta potensi dan kepribadian dari peserta yang dididik untuk melakukan dengan sadar akan usaha yang sudah terencana ataupun matang yang bertujuan dapat bermanfaat bagi dirinya sendiri, maupun bagi masyarakat serta bagi bangsa dan negara. Pendidikan merupakan upaya yang terencana dalam proses pembimbingan dan pembelajaran bagi individu agar berkembang dan tumbuh menjadi manusia yang mandiri, bertanggungjawab, kreatif, berilmu, sehat dn berakhlak mulia baik dilihat dari aspek jasmani maupun rohani. Sesuai dengan penelitian Tetep (2018) yang dilakukan pada mahasiswa di PPKn STKIP Garut dengan sampel sebanyak 40 orang dan dijelaskan bagaimana cara mengajarkan tentang 1) Literasi Media, 2) Pengajaran Mendalam nilai-nilai Pancasila dan Kewarganegaraan, dan 3) Integrasi Budaya Lokal. Melalui studi deskriptif hasil penelitian menunjukkan bahwa: 1) Pemanfaatan Teknologi dengan baik upaya kepada mahasiswa untuk bertindak secara bijak 75,5\%. 2) Pengajaran Nilai-Nilai Pancasila dan Kewarganegaraan dengan mempertegas jati diri bangsa, 66,5\% 3) Dengan Terintegrasi nilai-nilai perbedaan budaya lokal dapat meningkatkan pemahaman mahasiswa terhadap nilai-nilai keberagaman 85,4\%. Dengan memanfaatkan kearifan media teknologi dan informasi dapat memperkuat nilai-nilai kebhinekaan untuk menjaga persatuan agar jati diri bangsa tidak tercabut dan budaya lokal tetap menjadi tumpuan bangsa. 
Bagi mahasiswa magang sangatlah penting, karena akan menambah sebuah pengalaman begitupun juga bagi mahasiswa program studi PPKN tidak hanya melaksanakan praktik mengajar namun juga mengikuti praktik pemahaman hukum di Pengadilan Negeri Bojonegoro. Tempat praktik yang sesuai namun permasalahan lain yang terkait dengan pelaksanaan praktik pemahaman hukum maka hal ini membuat para mahasiswa merasa belum adanya ketercapaian dari tujuan dalam praktik pemahaman hukum. Praktik pemahaman hukum yang dilaksanakan di Pengadilan Negeri Bojonegoro bagi mahasiswa semester lima merupakan kegiatan yang hampir sama dengan magang namun bedanya bagi mahasiswa yang memiliki background pendidikan ini merupkan pengembangan mata kuliah hukum pidana dan hukum perdata jadi mahasiswa hanya hadir dan mengamati proses berjalannya persidangan. Namun beragam permasalahan yang dihadapi oleh mahasiswa akan muncul saat mengikuti praktik pemahaman hukum. Pada penelitian ini lebih memfokuskan pada analisis beragam fenomena dari sebuah masalah yang terjadi dan memberi solusi untuk program selanjutnya.

\section{KAJIAN PUSTAKA}

Pendidikan merupakan kebutuhan sekunder, pendidikan tetap memiliki arti sangat penting, sebab tanpa pendidikan manusia akan sulit berkembang dan bahkan menjadi golongan yang terbelakang. Dengan demikian pendidikan harus diarahkan untuk menghasilkan menusia yang berkualitas dan memiliki kompetensi yang bersaing, serta harus memiliki budi pekerti yang luhur dan moral yang baik. Empat pilar pendidikan saat ini dan masa depan yang dirancangkan oleh UNESCO yang perlu dikembangkan oleh lembaga pendidikan formal yang salah satunya adalah pendidikan tinggi, yaitu (1) learning to know (belajar untuk mengetahui), (2) learning to do ( belajar untuk melakukan sesuatu), (3) learning to be (belajar untuk menjadi seseorang ),(4) learning to live together (belajar untuk menjalani kehidupan bersama) (Elfian, Ariwibowo, \& Johan, 2018). (Suarta, 2010) menyatakan bahwa magang sangat penting dilakukan untuk relevansi nilai-nilai hasil hasil pendidikan untuk memperkecil kesenjangan keterampilan yang dimiliki lulusan dengan dunia kerja sehingga meningkatkan daya serap lulusan.. Sedangkan menurut (Sari \& Murwaningsih, n.d.) yang menyatakan, magang adalah teknik belajar yang melibatkan pengamatan individual pada pekerjaan dan penentuan umpan balik untuk memperbaiki kinerja atau mengoreksi kesalahan.

Menurut Inanna (2018), Dalam Undang-Undang Sistem Pendidikan Nasional No. 20 Tahun 2003 Bab II Pasal 3 menyatakan bahwa Pendidikan Nasional berfungsi mengembangkan kemampuan dan membentuk watak serta peradaban bangsa yang bermartabat dalam rangka mencerdaskan kehidupan bangsa, bertujuan untuk berkembangnya potensi peserta didik agar menjadi manusia yang beriman dan bertaqwa kepada Tuhan Yang Maha Esa, berakhlak mulia, sehat, berilmu, cakap, kreatif, mandiri, dan menjadi warga negara yang demokratis serta bertanggung jawab.

Sistem pelaksanaan progam magang yang sekarang masih belum efektif karena lemahnya koordinasi antara pihak-pihak yang terlibat, kurang tersetruktur dan kurang selektif, sehingga perlu penyempurnaan (Jawab \& Disiplin, 2018). Hasil penelitian (Gunarathne et al., 2010) dalam jurnalnya menuliskan bahwa permasalahan yang terjadi pada saat pelaksanaan magang yaitu pelaksanaan magang tidak sesuai dengan harapan, mahasiswa dan atasan memiliki tujuan atau prioritas yang saling bertentangan, kebosanan, komunikasi yang buruk, penyakit diderita mahasiswa praktikan, pekerjaan yang tidak sesuai dengan harapan, tidak ada pembimbing yang mengawasi, tidak mengetahui pihak yang harus dihubungi ketika menemui permasalahan, arah yang tidak jelas, tidak konsisten, atau 
bertentangan, terlalu banyak atau terlalu sedikit pekerjaan pekerjaan yang dilakukan, ekspektasi tentang pengetahuan atau keterampilan yang diharapkan, kurangnya umpan balik dan tujuan yang jelas tentang pembelajaran saat magang, banyak programyang kurang memuat konten akademik, dan harus dipertimbangkan tentang titik utama magang.

\section{METODE PENELITIAN}

Melalui pendekatan kualitatif deskriptif dengan jenis penelitian fenomenologi maka penelitian ini mengeksplorasi praktik pemahaman hukum dengan bertujuan untuk memperoleh berbagai deskripsi tentang permasalahan pada pelaksanaan praktik pemahaman hukum dan menggali sebuah informasi yang beragam melalui wawancara dengan mahasiswa yang mengikuti praktik pemahaman hukum secara langsung dan dosen Pembimbing, lokasi penelitian di Program Studi Pendidikan Pancasila dan Kewarganegaraan IKIP PGRI BOJONEGORO. Dari data primer diperoleh peneliti secara langsung dari hasil kuisioner terbuka yang disebar pada masing-masing koordinator dari dua kelompok dan hasil dari wawancara mendalam dengan 12 partisipan yang terdiri dari 10 mahasiswa dan 2 dosen pembimbing praktik pemahaman hukum serta catatan lapangan hasil penelitian. Data sekunder dari daftar mahasiswa program studi Pendidikan Pancasila dan Kewarganegaraan yang sedang mengikuti praktik pemahaman hukum. Data dikumpulkan sesuai prosedur pada penelitian mengikuti langkah dari

Gambar 1. Creswell (2014 : p. 307).

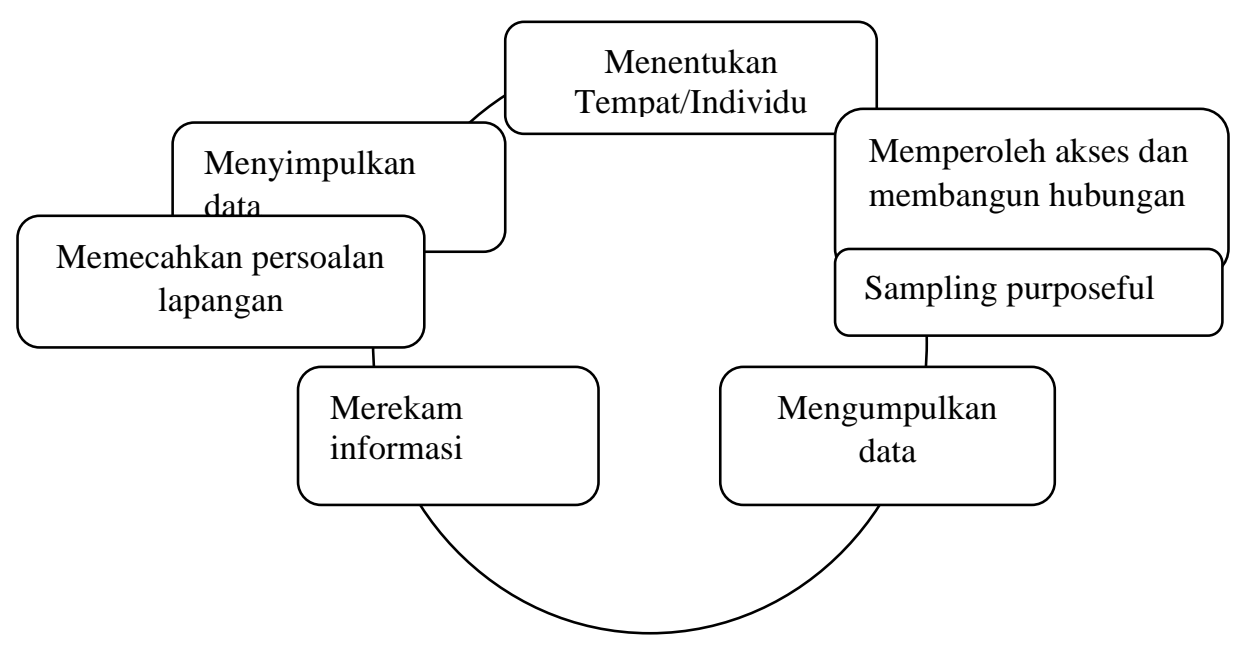

Analisis data mengikuti konsep yang diberikan Lodico, Spaulding,\& Voegtle (dalam Putra (2012: p. 97). Tahap- tahap analisis data sebagai berikut : 1) mengorganisir data dan melakukan pemeriksaan data dengan cermat, 2) melakukan pemeriksaan ulang terhadap data, 3) melakukan pengolahan data lebih lanjut, 4) melakukan analisis terkhir, membuat inteprestasi dan kesimpulan akhir berisi hasil temuan peneliti. Pengecekan keabsahan temuan berguna agar hasil dari penelitian dapat dipertanggungjawabkan, kredibilitas data penelitian diuji menggunakan dua teknik, yaitu perpanjangan pengamatan dimana peneliti akan kembali lagi ke lapangan setelah melakukan analisis data dan telah merumuskan sejumlah kategori untuk mengecek apakah kategori yang telah dirumuskan sesuai dengan data lapangan dan sesuai dengan perspektif para partisipan dan teknik triangulasi sumber mencari informasi lain tentang topik yang sama lebih dari satu sumber. Informasi ini didapatkan dari 10 mahasiswa yang mengikuti praktik pemahanan hukum di Pengadilan Negeri Bojonegoro dan kepada 2 
dosen pembimbing dari jurusan progam studi pendidikan pancasila dan kewarganegaraan serta triangulasi metode dilakukan dengan wawancara langsung dan penyeberkan beberapa kuisioner kepada mahasiswa yang sedang mengikuti praktik pemahaman hukum.

\section{HASIL DAN PEMBAHASAN}

1. Analisis Permasalaan dalam persiapan sebelum Praktik Pemahaman Hukum

Praktik pemahaman hukum adalah kegiatan dimana mahasiswa pendidikan pancasila dan kewarganegaraan mengamati proses berjalannya persidangan di Pengadilan Negeri Bojonegoro. Sebagai mahasiswa yang memiliki background pendidikan tentunya mengikuti praktik pemahaman hukum adalah kegiatan baru sebelum mahasiswa melaksanakan praktik mengajar pada sekolah-sekolah yang sudah ditentutkan oleh institut. Program studi Pendidikan Pancasila dan Kewarganegaraan memiliki kesempatan untuk mengikuti praktik pemahaman hukum di Pengadilan Negeri Bojonegoro selama dua minggu dan dibagi menjadi dua gelombang, sebagai pengembangan teori ilmu yang sudah didapat di perkuliahan dan untuk mengoptimalisasikan maka praktik pemahaman hukum ini sangat membantu bagi mahasiswa untuk belajar lebih mendalam mengenai hukum, tidak hanya sekedar datang, mengamati namun mahasiswa juga mencatat hal-hal yang belum jelas dan akan ada kelas khusus dimana mahasiswa akan menanyakan hasil pengamatannya pada Bapak Wakil Ketua dan didampingi oleh dosen pembimbing.

Dosen pembimbing sudah memberikan gambaran mengenai tempat dimana mahasiswa akan mengikuti praktik pemahaman hukum dan sebuah instansi yang dipilih sudah cukup jelas namun untuk penyusunan laporan praktik pemahaman hukum belum begitu dimengerti oleh mahasiswa mengenai teknik penulisannya.

Pembekalan yang dibutuhkan oleh mahasiswa saat mengikuti praktik pemahaman hukum di Pengadilan Negeri Bojonegoro sangatlah penting, namun pembekalan yang diberikan oleh dosen pembimbing terkait materi yang akan diberikan di Pengadilan Nanti dirasa kurang maksimal sehingga mahasiswa mengalaman permasalahan dalam mempersiapkan diri ketika sudah berada di Pengadilan Negeri. Meski sudah ditetapkan tempat untuk praktik pemahaman hukum namun mahasiswa yang memiliki background pendidikan harus benar-benar bisa mengingat kembali teori yang sudah di dapat saat dibangku perkuliahan. Berdasarkan permasalahan diatas maka seharusnya dosen pembimbing harus secara maksimal memberikan bekal berupa materi, teknik pelaksanaan saat mahasiswa melaksanakan praktik pemahaman hukum.

Informasi pelaksanaan yang kurang jelas akan membuat mahasiswa kesulitan dalam mengambil ijin cuti bagi yang sudah bekerja, mundurnya pelaksaan yang terjadwal akhir tahun 2019 ternyata terlaksana pada awal 2020 yaitu bulan februari akan membuat mahasiswa yang sudah terlanjur mengambil cuti bekerja akan reschedule pengajuan ijin cuti, namun hal ini tidak mudah untuk koordinasi dengan pihak tempat mereka bekerja. Selain itu, praktik pemahaman hukum yang dimulai pukul 07.00-16.00. Dari permasalahan diatas maka dosen pembimbing perlu membuat jadwal yang jelas terkait praktik pemahaman hukum serta memberikan surat permohonan bagi mahasiswa yang sudah bekerja sehingga dari pihak terkait mampu memberikan ijin cuti jika terjadi perubahan jadwal praktik.

Proposal dalam praktik pemahaman hukum yang dilaksanakan di Pengadilan Negeri Bojonegoro tentunya harus mengacu pada hal-hal yang dihadapi masahasiswa saat melaksanakan praktik pemahaman hukum. Namun bagi mahasiswa menyusun proposal adalah sebuah pengalaman yang baru, jika kurang jelasnya tata cara penyusunan maka akan membuat mahasiswa kesulitan dalam mengambil tema. Hal tersebut seharusnya dosen 
pembimbing mendampingi mahasiswa saat penulisan proposal sehingga apa yang dituliskan dalam proposal searah dengan apa yang harus di tulis dalam laporan akhir praktik pemahaman hukum.

2. Analisis permasalahan dalam Pelaksanaan Praktik Pemahaman Hukum

Praktik pemahaman hukum yang dilaksanakan pada bulan Februari-Maret 2020 bertepatan dengan maraknya wabah covid -19 hal ini menjadikan mahasiswa yang mengikuti praktik pemahaman hukum semakin menambah kepanikan,disamping itu surat edaran dari perguruan tinggi untuk tetap dirumah saja, namun ada beberapa mahasiswa yang berasumsi bahwa praktik pemahaman hukum juga dipadatkan, karena ketidaktahuannya sehingga membuat pihak terkait memakluminya, bagi mahasiswa yang lain harus tetap mengikuti kegiatan praktik pemahaman hukum dengan mengikuti protokol kesehatan yang sudah ditentukan. Dari permasalahan diatas maka seharusnya dosen berkomunikasi dengan pihak Pengadilan Negeri untuk memadatkan jadwal karena wabah covid-19 ini memang sudah meluas dan perlu kewaspadaan yang tinggi.

Mahasiswa yang memiliki background pendidikan untuk mengikuti praktik pemahaman hukum di Pengadilan Negeri, meski mereka hanya datang, menyaksikan sidang dan berdiskusi tentang hal-hal yang perlu di tanyakan namun perlu adanya pendampingan terlebih dari beberapa dosen pembimbing yang belum maksimal dalam memberikan sebuah arahan dan pendampingan kepada mahasiswa ketika melaksanakan praktik. Tugas dosen pembimbing yang kurang jelas menjadikan mahasiswa kesulitan saat menghubungi dosen pembimbing, sehingga mengakibatkan kurangnya komunikasi antara mahasiswa dengan dosen. Dosen juga merasa tidak diberikan jadwal yang paten sehingga merasa kurang dilibatkan dalam kegiatan praktik pemahaman hukum sehingga mengakibatkan canggung untuk datang ke Pengadilan Negeri tanpa jadwal yang resmi. Meski kegiatan praktik pemahaman hukum ini merupakan pengembangan dari mata kuliah hukum pidana dan hukum perdata bukan berarti tidak ada jadwal yang resmi dari program studi. Dari permasalahan tersebut maka perlu adanya jadwal yang resmi untuk dosen pembimbing tugas-tugas yang harus dilakukan oleh pembimbing selama mendampingi praktik pemahaman hukum karena kegiatan praktik pemahaman hukum memberikan manfaat yang luar biasa bagi mahasiswa dan program studi.

Praktik pemahaman hukum yang dilaksanakan di Pengadilan Negeri Bojonegoro dan dengan jadwal masuk hari senin-jumat pukul 08.00-16.00 setiap harinya dan libur untuk hari sabtu dan minggu, namun jarak tempuh yang jauh bagi mahasiswa yang berdomisili di Randublatung, Cepu, senori Tuban dan Tambakrejo Bojonegoro harus berangkat lebih awal selama praktik berlangsung. Sehingga disini mahasiswa terkendala waktu dan jarak tempuh perjalanan. Dari permasalahan diatas seharusnya dosen dan pihak Pengadilan Negeri berkoodrinasi untuk memberi kelonggaran waktu bagi mahasiswa yang jarak tempuhnya jauh meski mahasiswa datang telat namun tidak mendapat sanksi apa-apa, namun untuk menjaga kedisiplinan mahasiswa dan demi lancarnya kegiatan praktik pemahama hukum perlu adanya koordinasi yang jelas.

3. Analisis Permasalahan Setelah Praktik Pemahaman Hukum

Panduan penulisan yang kurang jelas akan membuat mahasiswa kesulitan untuk menulis laporan akhir dalam kegiatan praktik pemahaman hukum, ketika menulis laporan akhir mahasiswa kurang berkomunikasi dengan dosen pembimbing sehingga mereka menuliskan sesuai dengan pemahamannya sendiri. Berdasarkan permasalahan ini maka sebaiknya mahasiswa dalam penulisan laporan akhir sayogyannya berkonsultasi dengan dosen pembimbing sehingga akan tepat dalam menuliskan hal-hal yang perlu di tulis dalam penyusunan laporan akhir. 


\section{SIMPULAN DAN SARAN}

Praktik pemahaman hukum adalah kegiatan dimana mahasiswa pendidikan pancasila dan kewarganegaraan mengamati proses berjalannya persidangan di Pengadilan Negeri Bojonegoro. Sebagai mahasiswa yang memiliki background pendidikan tentunya mengikuti praktik pemahaman hukum adalah kegiatan baru sebelum mahasiswa melaksanakan praktik mengajar pada sekolah-sekolah yang sudah ditentutkan oleh institut.. Berdasarkan hasil penelitian tentang analisis permsalahan mahasiswa Program Studi Pendidikan Pancasila dan Kewarganegaraan adalah kurang lengkapnya dalam memberikan pembekalan, informasi yang kurang jelas terkait waktu pelaksanaan, Penyusunan proposal praktik pemahaman hukum,tetap masuk meski ditengah maraknya covid-19, peran dosen pembimbing yang kurang maksimal, jarak tempuh yang jauh, penyusunan laporan praktik pemahaman hukum.

\section{DAFTAR PUSTAKA}

[1] Creswell,J. (2014). Penelitian Kualitatif \& Desain Riset: Memilih diantara Tiga Pendekatan. Yogyakarta : Pustaka Pelajar.

[2] Effrisanti, Y. (2015). Pembelajaran Berbasis Proyek Melalui Program Magang Sebagai Upaya Peningkatan Soft Skills Mahasiswa. Eksis, X(1), 28-41.

[3] Elfian, E., Ariwibowo, P., \& Johan, R. S. (2018). Peran Pendidikan Tinggi dalam Meningkatkan Minat Masyarakat untuk Produktivitas Pendidikan. Sosio E-Kons, 9(3), 200. https://doi.org/10.30998/sosioekons.v9i3.1870

[4] Gunarathne, K. U. H. K., Maduranga, S. A. K., Rathnayake, K. G. K. H., Fernando, P. U. W. E., Kaushalya, K. V. S. G., \& Wijesekara, T. N. (2010). Problems of Internship : Opinions of the Management Undergraduates of the University of Sri Jayewardenepura, 1(1), 82-90.

[5] Inanna, I. (2018). Peran Pendidikan Dalam Membangun Karakter Bangsa Yang Bermoral. JEKPEND: Jurnal Ekonomi Dan Pendidikan, 1(1), 27. https://doi.org/10.26858/jekpend.v1i1.5057

[6] Jawab, T., \& Disiplin, D. A. N. (2018). ANALISIS EFEKTIFITAS CBET ( COMPETENCY BASE EDUCATION AND TRAINING ) SEBAGAI UPAYA PENINGKATAN SOFT SKILLS , 15(2), 155-160.

[7] Putra.N. (2012). Metode Penelitian Kualitatif Pendidika.Jakarta. PT. Raja Grafindo Persada.

[8] Sari, B. L., \& Murwaningsih, T. (n.d.). No Title, 1-9.

[9] Suarta, I. M. (2010). Hubungan sistem pembelajaran, lingkungan belajar, konsep diri dan pengembangan, 24-41.

[10] Tetep (2018). Reorientation of Values of The Indonesian Diversity (ke-Bhineka-an Indonesia) to Reaffirming the National Identity. https://download.atlantispress.com/article/25906011.pdf 